\title{
A Comparative Approach to Notions of Good Citizenship
}

\author{
Cristóbal Villalobos, María Jesús Morel, and Ernesto Treviño
}

\begin{abstract}
This chapter seeks to understand the relationship between profiles of good citizenship and sociodemographic, economic, political, and cultural country variables, seeking to deepen the understanding of good citizenship in the participating countries of IEA's International Civic and Citizenship Education Study (ICCS) 2016. Using a comparative policy approach, the chapter explores three groups of factors that may relate to contextual differences in notions of good citizenship: (i) political (forms of democracy, legal system, levels of corruption, and authoritarianism); (ii) economic (growth and economic inequality); and (iii) cultural (values and norms, levels of tolerance, role of the internet). The results show that, although there are common patterns among all or most countries (low proportion of anomic profiles, high proportion of comprehensive and socially-engaged profiles), there are also important differences in the distribution of these profiles across countries, depending on the geographic location and type of government regime. National income and use of social media are the two most significant variables to explain differences in notions of good citizenship between countries.
\end{abstract}

Keywords Citizenship norms $\cdot$ Comparative $\cdot$ Country income $\cdot$ International Civic and Citizenship Education Study (ICCS)

\footnotetext{
C. Villalobos $(\varangle) \cdot$ M. J. Morel

Centro de Estudios de Políticas y Prácticas en Educación (CEPPE-UC), Pontificia Universidad Católica de Chile, Santiago, Chile

e-mail: clvillal@uc.cl

M. J. Morel

e-mail: mjmorel@uc.cl

E. Treviño

Facultad de Educación and Centro de Justicia Educacional, Pontificia Universidad Católica de Chile, Santiago, Chile

e-mail: ernesto.trevino@uc.cl
} 


\section{Introduction}

"Good citizenship" is a multidimensional concept, which includes a series of values, actions and norms (see Chap. 2). In this regard, the idea of the "good citizen" refers to the sense of belonging of a group of people, and how they believe they should behave within their community. Since the idea of good citizenship is linked to a particular community - generally a nation or state-its definitions vary in relation to the place of belonging (Adler and Moi 2011; Eder 2017; Goering 2013; Hooghe et al. 2016). This implies that the idea of good citizenship depends on the historical and geographic context.

This chapter analyzes the concept of good citizenship, seeking to understand differences in notions of the good citizen that exist in the participating countries of the International Civic and Citizenship Education Study (ICCS) 2016, coordinated by the International Association for the Evaluation of Educational Achievement (IEA). In this regard, we use what Bray et al. (2014) define as the comparative policy approach, which argues that the differences between countries are related to the way in which people develop their values, norms, and perceptions about the world. We start from the assumption that at least some of the differences in what young people regard as good citizenship are related to the country where they live and have been socialized.

Our central hypothesis is that country differences in notions of good citizenship can be mainly explained by three types of factors: (i) political (forms of democracy, legal system, levels of corruption and authoritarianism); (ii) economic (growth and economic inequality); and (iii) cultural (values and norms, role of internet, levels of tolerance). In this regard, we propose that recent global phenomena such as growth in inequalities, financial delocalization, technologization of society, climate change, fragility of democracy, and increased religious or political intolerance have produced changes in the idea of good citizenship, although these changes vary in intensity and magnitude in different countries.

To meet these objectives, the chapter is organized into four sections. The first summarizes the conceptual framework, focusing on describing the academic literature that analyzes how different factors may affect the notions of good citizenship, with a special focus on youth. The second section describes methodological elements of the chapter, including the variables, data, and analytical techniques used. The third section describes the research results, showing the distribution of good citizenship profiles among countries and regions. Finally, the last section discusses the main conclusions. 


\section{Conceptual Framework: A Situated Perspective of Good Citizenship}

Today's world is characterized by important changes in structures and perceptions of social and civic issues. In this sense, phenomena such as the increase in economic inequalities and the rise of top incomes (Atkinson and Piketty 2010), the relevance of climate change and the threat to human survival (Klein 2017), the fragility of democracy, the growth of populism and the increase of political, religious, and cultural intolerance (Hobsbawm 2013) have generated key transformations in the configuration of social issues.

Within this global context, the idea of citizenship and the characteristics of a good citizen have undergone important transformations. On the one hand, the increase in risks associated with climate change has created tensions in the discussion of citizenship at the national level, introducing the focus to global citizenship and responsible consumption (Atkinson 2012; Woolf 2010). Secondly, the evidence of growing social inequalities has drawn attention to processes such as global migration and gender inequalities, highlighting the need to expand the notion of good citizenship to incorporate aspects related to solidarity and social fraternity (Bolzendahl and Coffé 2009; Fernández and Kriegbaum 2017). Finally, the increase in political and religious intolerance between and within countries has brought into question the role of citizenship in social cohesion, showing how active citizenship can be important for the defense of human rights, democracy, and social tolerance (Altikulaç 2016; Kennelly 2011), while playing, for example, a central role in post-conflict contexts (Russell and Quaynor 2017).

Despite their universal importance, these phenomena are developing with different intensities and magnitudes around the world. For this reason, the idea of the good citizen is always a situated concept. Based on a review of the academic literature, we identify three groups of factors that may influence the notion of good citizenship: economic, cultural, and political.

In the economic field, both growth and economic inequality are indicated as factors that could influence notions of good citizenship. In the case of economic growth, the post-materialist theory developed by Inglehart (1971) has suggested that people in the fastest growing societies change their priorities, starting from an emphasis on general, impersonal, and political objectives (such as "maintain the order of a nation," "protect freedom of expression," or "fight for price control") to values more related to individual and personal desires, focused on self-interest and individual self-realization (Inglehart 1979). In this regard, it should be expected that in these societies the idea of the good citizen would be less related to rights and duties, emphasizing other aspects such as solidarity or personal involvement with the social and political events of the country. In the case of economic inequalities, some authors have shown that one of the social consequences is the loss of a sense of belonging to what Anderson (1983) called "imagined communities." In this sense, inequalities create a fragmentation of citizenship, causing many people to feel distant from others, losing trust in a country or nation (Tesei 2014; Yamamura 2008). As a 
result, it is possible to predict that in societies with high levels of inequalities people have a more anomic and/or indifferent perspective of good citizenship.

In relation to cultural variables, three topics have emerged in the last two decades. First, a large body of literature has studied how values, ethical traditions, and worldviews may influence the idea of good citizenship. The most interesting debate is that of "Asian values" and their relationship to citizenship. In a nutshell, different authors have proposed that East Asian countries have a notion of good citizenship strongly linked to duty-based values, due to the importance of Confucianism and Taoism, both of which emphasize the idea of virtue in governance, as well as Buddhism, which emphasizes the notion of good behavior. This contrasts with liberal and communitarian norms more prevalent in Western societies (Chang 2016; Dalton and Ong 2005; Kuang and Kennedy 2014). Secondly, it has been indicated that polarization, understood as the increase of religious, social, gender, or immigrant divisions within a country, is an important factor for understanding the configuration of citizenship, as it may undermine the basic cohesion of a nation (Esteban et al. 2012; Esteban and Ray 2011). Faced with these phenomena, citizens could engage in processes of social anomie, a detachment from a shared notion of citizenship. Finally, research has proposed that new technologies—especially the internet—could be playing a role in the configuration of good citizenship. Regarding this point, two different theories have been proposed, representing the cyber-optimistic and cyber-pessimistic visions (Soriano 2013). While some researchers have shown how technologies can be an incentive to develop greater control and criticism of governments, encouraging a more active conception of citizenship (Castells 2015), others have shown that excessive use of technologies weakens personal networks, which could lead to a decrease in the daily discussion of social and political problems and a loss of the importance of citizenship (Morozov 2011). In this way, technology could provoke contradictory processes regarding concepts of good citizenship.

Finally, there are political factors that may affect notions of citizenship. First, the type of government (liberal democracies, deliberative democracies, autocracies, etc.) can permeate the concept of the good citizen, due to the greater or lesser distance between the State and citizens (Mayne and Geißel 2018). In this regard, it is possible to hypothesize, for example, that in autocracies the focus of good citizenship would be more on duties and compliance with the law, while deliberative democracies would generate a notion of citizenship that is based mainly on active participation. On the other hand, there is also a possible relationship between certain state practices (such as corruption levels, the magnitude of a country's clientelist relationships between politicians and the population or the effectiveness of the government) and the idea of good citizenship (see Chap. 6). In this case, countries that have governments with lower levels of corruption and clientelism, as well as with greater levels of effectiveness, are expected to be associated with more comprehensive visions of citizenship, which are not necessarily limited to the fulfillment of duties. 


\section{Method}

\subsection{Dependent Variable}

The outcome variables are the profiles of good citizenship. Using data from IEA's ICCS 2016 (Schulz et al. 2018), we selected a set of 12 items for students to evaluate regarding the importance of different behaviors for being a good adult citizen, using a four-point Likert-type scale. With this information, five profiles are generated, using a latent class analysis approach (for the specific description of the dataset and method, see Chap. 3). The five profiles are: (i) duty-based, with an idea of good citizenship associated especially with social norms; (ii) socially engaged, with an understanding of good citizenship related to environmental and local issues; (iii) comprehensive, with a holistic conception of good citizenship; (iv) monitorial, with an understanding of good citizenship as a passive exercise; and (v) anomic, with low levels of adherence to all indicators.

\subsection{Independent Variables}

The purpose of this chapter is to explore the relationship between profiles of good citizenship and sociodemographic, economic, political, and cultural country variables. To achieve this purpose we use data from ICCS 2016, specifically three scales from the student questionnaire: (i) student endorsement of gender equality (GENEQL), an index that assesses whether students agree with an affirmation related to equal political rights between men and women (example: "Men and women should have equal opportunities to take part in government") and receive equal treatment (example: "Men and women should get equal pay when they are doing the same jobs"); (ii) student endorsement for equal rights for immigrants (IMMRGHT), which evaluates student disposition to support the idea that people of other ethnicities or races should have the same political opportunities, be treated with respect, and have the same rights; and (iii) student engagement with social media (SOCMED), an index that measures the influence of the use of the internet to inform, share, and comment on political or social issues. In all cases, we use the average score for each country, using the sample weights. ${ }^{1}$

In addition to ICCS 2016 data, we use data from other sources to analyze the political, economic, and cultural characteristics of the countries. Using World Bank Data, ${ }^{2}$ we obtained information about the Gini coefficient, a measure of income inequality that fluctuates between 0 and 1 , where 0 corresponds to perfect equality (all have the same income) and where 1 corresponds to perfect inequality (one person

\footnotetext{
${ }^{1}$ Higher values indicating more positive attitudes toward equal rights for women, immigrants, and higher frequencies of engagement.

${ }^{2}$ https://data.worldbank.org.
} 
has all income and the others have none). ${ }^{3}$ From the Maddison Project Database, ${ }^{4}$ we obtained the Gross Domestic Product (GDP) per capita measure, which is one of the most used international measures of a country's economic growth, and reflects the monetary value of all finished goods and services made within a country in 2016. Finally, we use the V-Dem dataset V9 (Coppedge et al. 2019) for variables related to political factors. Specifically, we use two variables from this dataset: (i) regimes of the World (v2x_regime), which classifies each regime, considering the competitiveness of access to power and liberal principles in: (a) liberal democracy; (b) electoral democracy; and (c) autocracy; and, (ii) the neopatrimonial rule index (v2x_neopat), an index that summarizes the institutional "quality" of democracy, including factors like vote buying, executive respect of the constitution, high and low court independence, autonomy of the electoral management body, executive embezzlement and theft, executive bribes and corrupt exchanges, and legislative and judicial corruption. The index is formed by taking the reversed scale (higher scores $=$ more neopatrimonialism) for a Bayesian factor analysis model of the indicators.

\subsection{Analytical Strategy}

We employed descriptive statistics to account for the distribution of good citizenship profiles between countries, showing the main similarities and differences in a comparative perspective. The estimates are survey design descriptive estimates. As such, these are the expected proportions of civic norm profiles between participating countries. Since the objective of this chapter is to understand the differences in notions of good citizenship in the 24 participating countries of ICCS 2016, using a comparative analysis seems appropriate in order to explain either commonality or diversity (Manzon 2014). Although the purpose of quantitative studies is deduction, theory or hypothesis testing, and verification (Fairbrother 2014), the approach of this chapter is not confirmatory but rather, it is a first approximation of what might explain the notions of good citizenship of the students participating in the study.

Experts in this method of analysis recommend special care when comparing regional blocs, countries, cultures, or other geographical/local groups, being aware of the plural identities within the regions and avoiding falling into stereotypes (Bray et al. 2014). It is also important to establish comparability parameters between the units of analysis, in this case, the participating countries of the ICCS 2016, which is difficult to ensure in these types of studies (Bray et al. 2014), so we have added more information about each unit along with the complementary data previously described.

\footnotetext{
${ }^{3}$ Only four countries had a value for the year 2016, so the value of the year closest to 2016 was used. Of the 24 countries in the sample, only Hong Kong did not have a Gini coefficient.

${ }^{4}$ https://www.rug.nl/ggdc/historicaldevelopment/maddison.
} 


\section{Results}

As expected, the distribution of the different profiles varies among the 24 countries (see Fig. 1). In the case of the comprehensive profile, the variation is considerable, since there are countries (such as Korea or Italy) where more than $70 \%$ of students are in this profile, while in Belgium (Flemish), the Netherlands, North Rhine-Westphalia, and Estonia no more than $20 \%$ of students are in the comprehensive profile. In the case of the socially-engaged profile, the variation is smaller, since in an important number of countries about $30 \%$ of students are classified in this profile. However, the case of Korea is striking, with almost no students classified as socially engaged. There are also important differences regarding the duty-based notion of good citizenship, with a low percentage of students in countries such as Mexico and Colombia in this profile $(0.7 \%$ and $0.8 \%$, respectively), while in the case of Denmark nearly half of

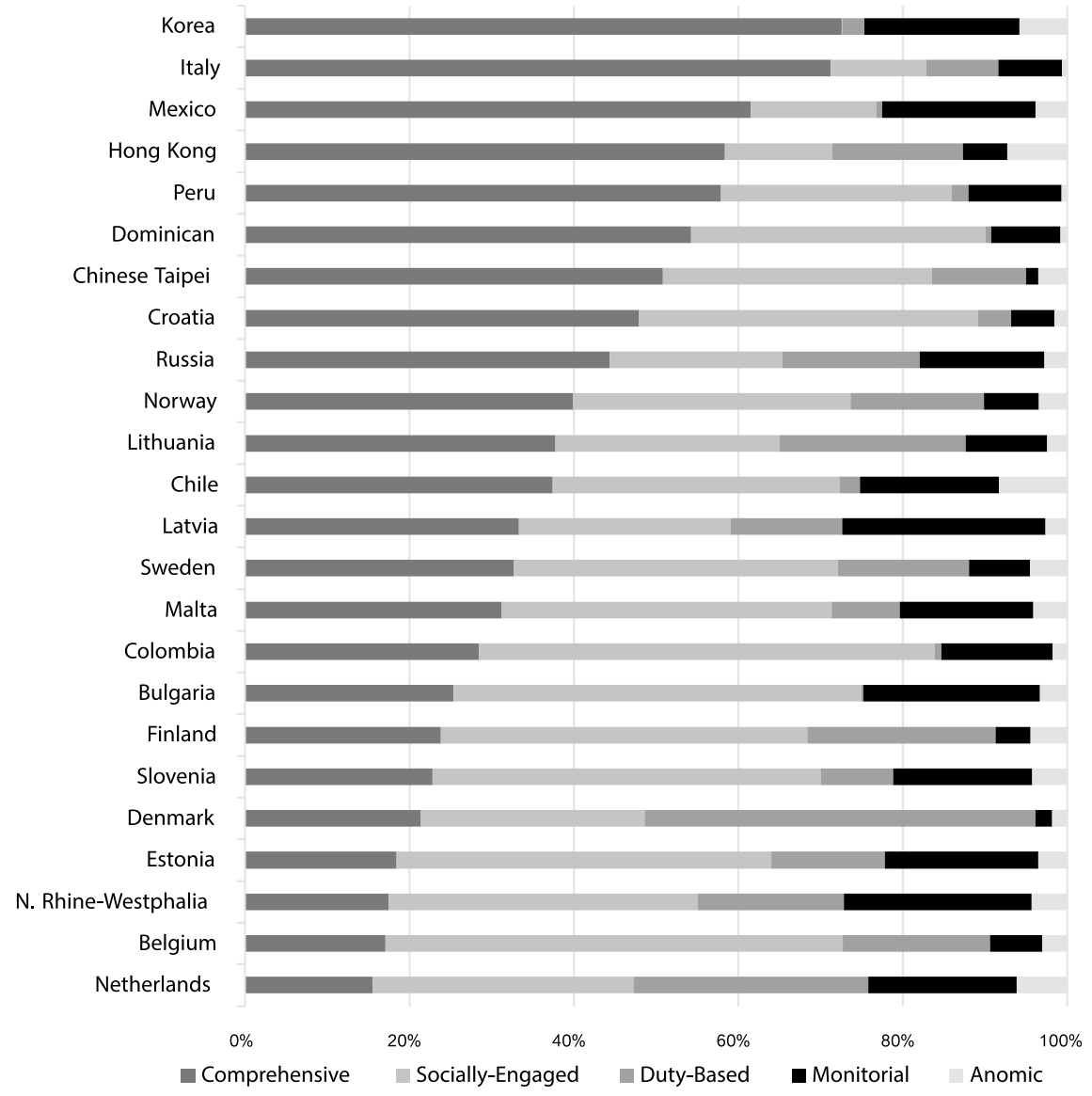

Fig. 1 Profile distribution by country 
the student population (47.6\%) is in this category. In terms of the monitorial profile, in most countries about $15 \%$ of the sample tends to be classified in this profile, although in countries such as Latvia $(24.7 \%)$, Bulgaria $(21.5 \%)$, or the state of North Rhine-Westphalia (22.9\%) this percentage is higher, while Chinese Taipei shows the lowest percentage (1.5\%). Finally, the anomic profile distribution is very similar among countries, although Chile stands out with $8.3 \%$ of students grouped in this profile.

Despite these differences, there are also common patterns that are important to highlight. First, in almost all countries (except the Netherlands and Denmark) more than $50 \%$ of students tend to develop comprehensive or socially-engaged notions of good citizenship. These two profiles emphasize holistic visions of the idea of good citizenship (see Chap. 2), which are not limited to the fulfillment of duties, while incorporating aspects related to respect for the environment and human rights (in the case of socially-engaged students), as well as a provision for active participation (in the case of comprehensive students). This finding is very important because it confirms that a high percentage of young people can be regarded as involved citizens. Secondly, in most countries (again, with the exception of Denmark) the more "classic" profile of good citizenship, based primarily on respect for norms (duty-based profile), does not describe the majority of young people, which is in line with the conclusions of Dalton (2008), who pointed out the generational change in patterns of understanding of good citizenship in recent decades. Finally, all countries have a low proportion of anomic students, in no case exceeding $10 \%$, which seems to show that an important part of the population develops a disposition from an early age to actively participate in the civic arena instead of being disinterested in political and social issues.

After observing the distribution of profiles in each country, we proceeded to analyze the grouping of countries by geographical area and type of regime. In the first case, the countries were grouped into three groups: Europe $(\mathrm{N}=16)$, Latin America $(\mathrm{N}=5)$, and Asia $(\mathrm{N}=3)$. It is possible to observe (see Fig. 2) that Asia concentrates the highest percentage of comprehensive students (60.6\%) compared to other profiles, which is in line with the discussion of "Asian values." In Latin America nearly half of students are in this profile with $47.9 \%$, but the percentage of socially-engaged students closely follows with $33.9 \%$. The high percentage of comprehensive students in Asia implies that, in this region, active forms of participation are considered ethical ways of being a good citizen, understanding participation as a moral duty and not only as an action to solve problems (Chang 2016). In Latin America, the dutybased profile concentrates the lowest percentage of students $(1.3 \%)$, which could be related to historical aspects, such as the less legalistic culture and an oral tradition. The socially-engaged profile predominates in Europe, which may be in line with theories that in more developed, post-industrial and post-materialistic societiesonce basic needs are fulfilled-citizens engage with issues beyond the norms and are more linked to self-interest and individualization processes.

When we look at the distribution of profiles by type of regime we find three classifications: autocracy $(\mathrm{N}=2)$, which refers to those political regimes without multiparty elections; electoral democracy $(\mathrm{N}=9)$ de facto free and fair multiparty 


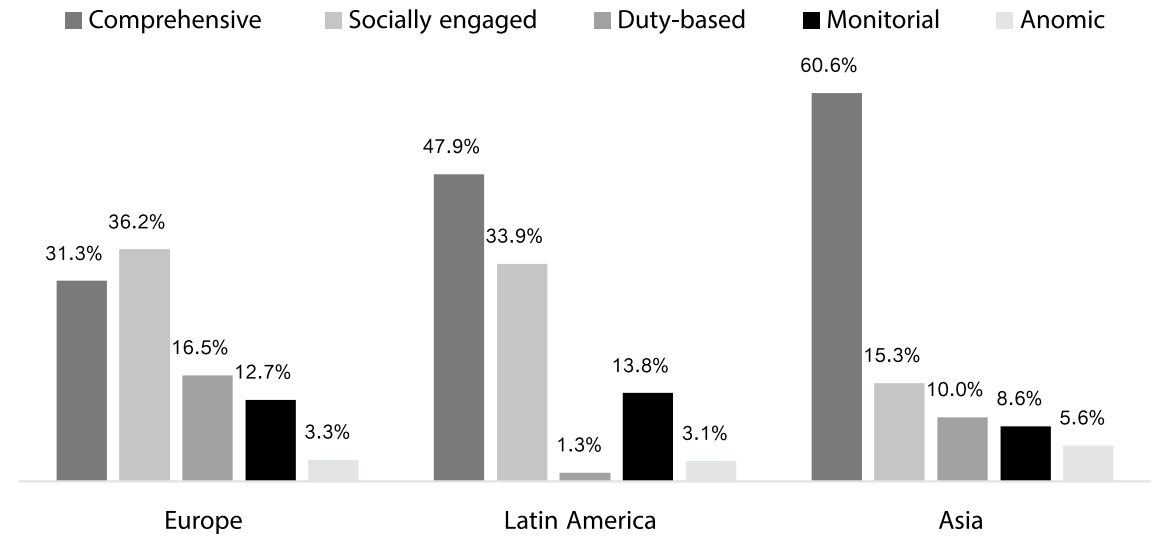

Fig. 2 Profile distribution by geographical area. Notes Europe = Belgium (Flemish), Bulgaria, Croatia, Denmark, Estonia, Finland, North Rhine-Westphalia, Italy, Latvia, Lithuania, Malta, the Netherlands, Norway, Russia, Slovenia, Sweden. Latin America $=$ Chile, Colombia, Dominican Republic, Mexico, Peru. Asia = Chinese Taipei, Hong Kong, Korea

elections, but access to certain civil liberties is more restricted; and liberal democracy $(\mathrm{N}=13)$ free and fair multiparty elections and guaranteed access to civil liberties. This latter type of regime mainly groups European countries. The percentage distribution by type of regime (see Fig. 3) of the five profiles of good citizenship behaves in a similar way as when the participating countries are grouped by geographical area.

Comprehensive Socially engaged Duty-based Monitorial Anomic

\section{$51.4 \%$}

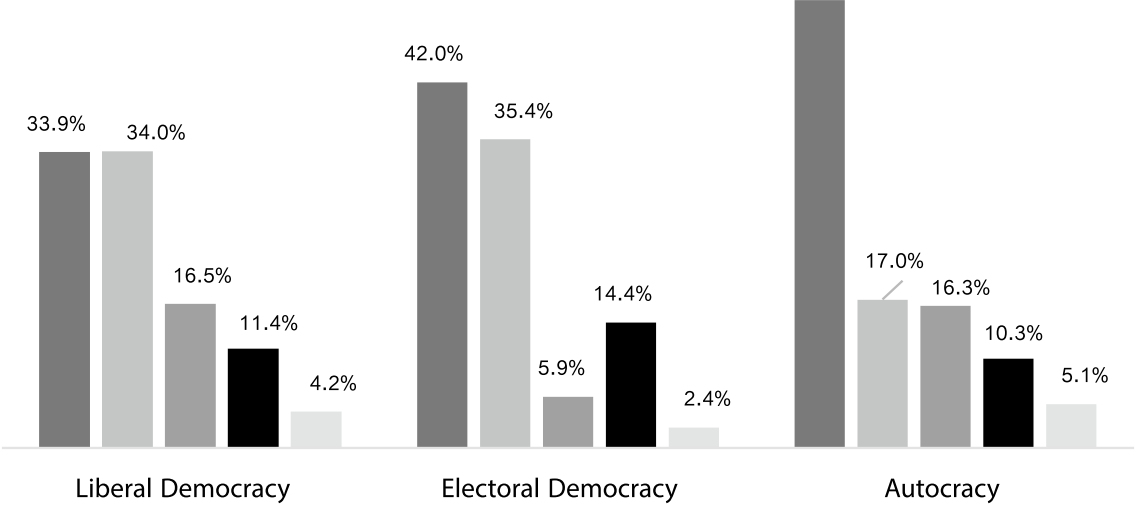

Fig. 3 Distribution of profiles by regime. Notes Liberal Democracy = Belgium (Flemish), Chile, Chinese Taipei, Denmark, Estonia, Finland, North Rhine-Westphalia, Italy, Korea, the Netherlands, Norway, Slovenia, Sweden. Electoral Democracy = Bulgaria, Colombia, Croatia, Dominican Republic, Latvia, Lithuania, Malta, Mexico, Peru. Autocracy = Hong Kong, Russia 


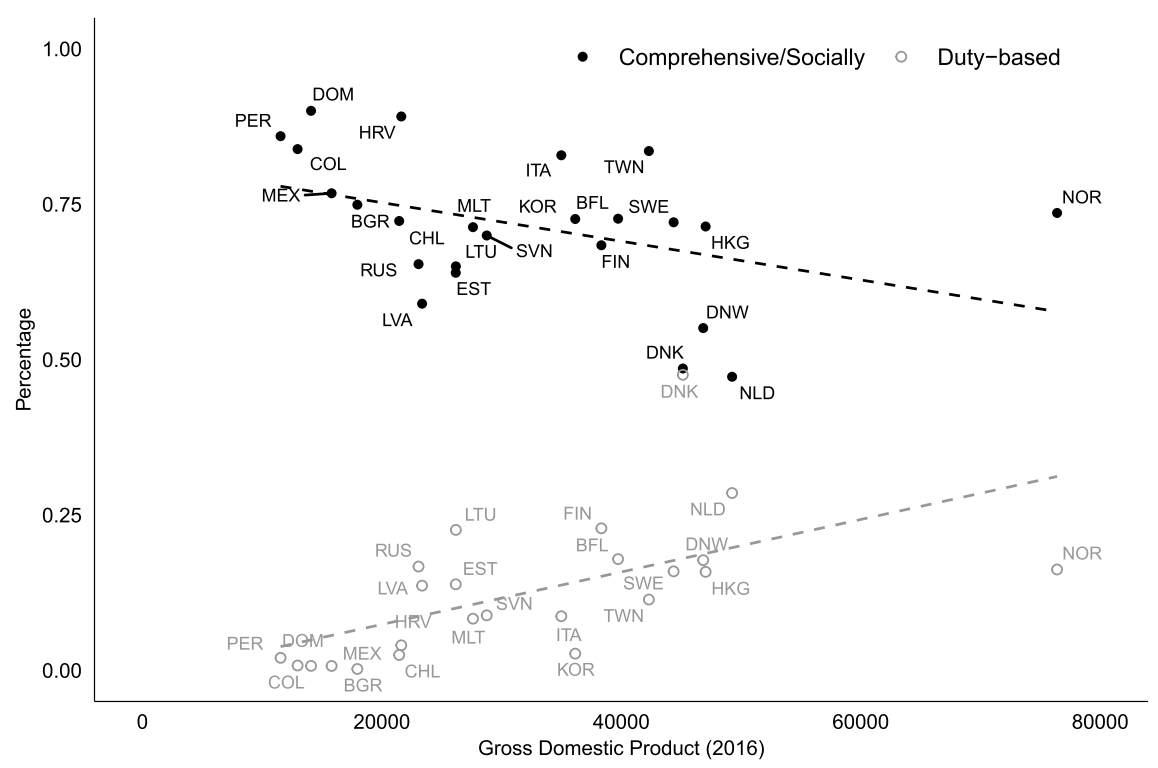

Fig. 4 Relationship between comprehensive/socially engaged and duty-based profiles and Gross Domestic Product in 2016. Notes LVA $=$ Latvia, DNW = North Rhine-Westphalia, BGR $=$ Bulgaria, $\mathrm{KOR}=$ Korea, $\mathrm{MEX}=$ Mexico, $\mathrm{EST}=$ Estonia, $\mathrm{NLD}=$ The Netherlands, $\mathrm{CHL}=$ Chile, $\mathrm{SVN}=$ Slovenia, MLT $=$ Malta, RUS $=$ Russia, $\mathrm{COL}=$ Colombia, $\mathrm{PER}=\mathrm{Peru}, \mathrm{LTU}=$ Lithuania, $\mathrm{DOM}$ $=$ Dominican Republic, ITA = Italy, $\mathrm{SWE}=$ Sweden, $\mathrm{NOR}=$ Norway, $\mathrm{BFL}=$ Belgium $($ Flemish $)$, $\mathrm{HKG}=$ Hong Kong, HRV $=$ Croatia, FIN $=$ Finland, DNK $=$ Denmark, TWN $=$ Chinese Taipei

Now we turn to analyzing the relationship between the citizenship profiles and the economic, political, and cultural variables. As GDP ${ }^{5}$ per capita increases, the percentage of comprehensive and socially-engaged students (jointly) decreases, while the percentage of duty-based students increases (see Fig. 4). The only case where these percentages intersect is in Denmark, where combining the comprehensive and socially-engaged profiles $(48.6 \%)$ is equivalent to the duty-based percentage (47.6\%). These results do not necessarily go in the direction proposed by Inglehart (1979) about post-materialism, since the duty-based perspective increases with economic growth. However, it is important to note that such a relationship is influenced by the higher percentages of duty-based students in Northern Europe and Scandinavian countries, which also have higher levels of GDP per capita (see, for example, Norway).

When comparing countries according to their percentage of more holistic profiles (comprehensive and socially engaged) and the level of inequality, Fig. 5 shows that countries with the highest Gini index values have higher percentages of those students who are committed to participate either as comprehensive or socially-engaged citizens. This same analysis with the monitorial and anomic profiles shows that there is

${ }^{5}$ For the analysis of this variable, and for those that come next that are not from ICCS 2016, the North Rhine-Westphalia region is not included, since there are no values at the state level. 


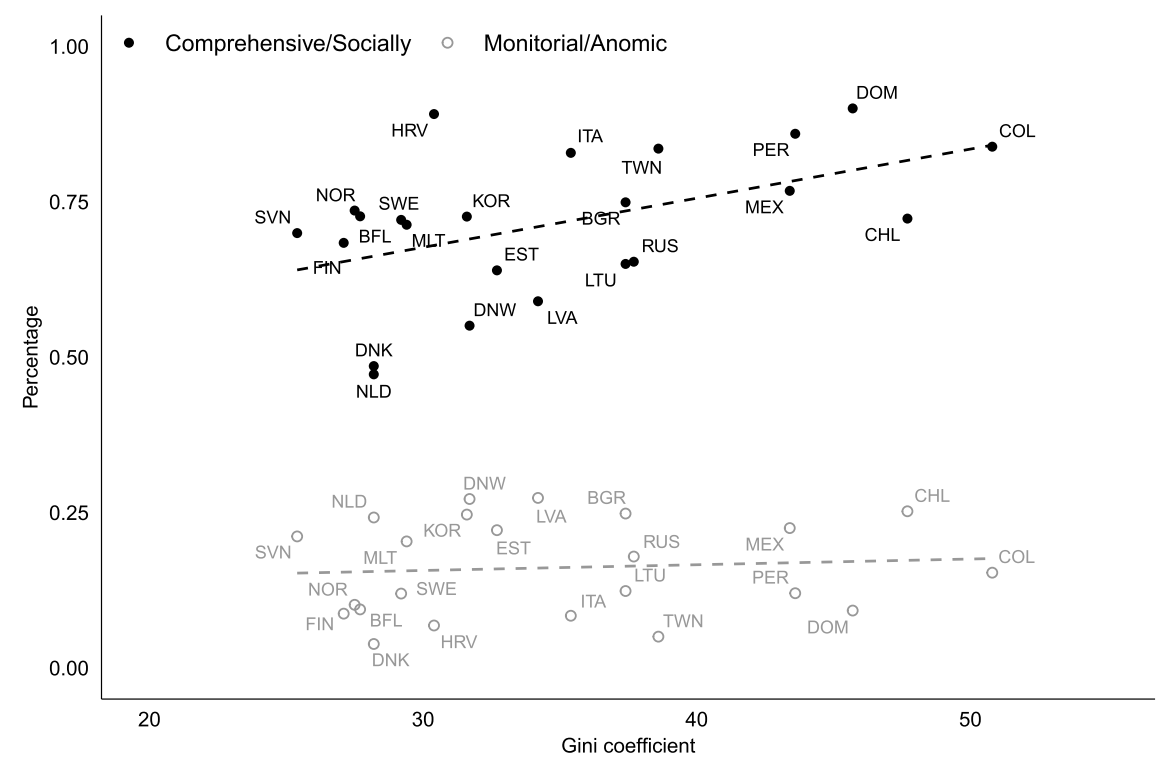

Fig. 5 Relationship between comprehensive/socially engaged and monitorial/anomic profiles and Gini coefficient. Notes $\mathrm{LVA}=$ Latvia, DNW = North Rhine-Westphalia, BGR = Bulgaria, KOR $=$ Korea, $\mathrm{MEX}=$ Mexico, EST $=$ Estonia, $\mathrm{NLD}=$ The Netherlands, $\mathrm{CHL}=\mathrm{Chile}, \mathrm{SVN}=$ Slovenia, MLT = Malta, RUS = Russia, COL = Colombia, PER = Peru, LTU = Lithuania, DOM $=$ Dominican Republic, ITA = Italy, SWE = Sweden, NOR = Norway, BFL = Belgium (Flemish), $\mathrm{HKG}=$ Hong Kong, HRV = Croatia, FIN = Finland, DNK = Denmark, TWN = Chinese Taipei

not a clear pattern, since countries with a high percentage of these profiles such as Latvia (27.4\%) have a Gini index value equal to or less than the average of the 23 countries.

Regarding the cultural variables that are proxy of cultural distance, relating the different profiles with the values of students' endorsement of gender equality and equal rights for all ethnic/racial groups, separately, gives differing results. On the one hand, there is a negative relationship between support for equality of rights of both females and ethnic groups, and the percentage of monitorial and anomic students. On the other hand, the higher the level of support for gender and ethnic equality, the higher the percentage of students in the comprehensive profile. ${ }^{6}$ This makes sense within the conceptual framework where this type of polarization is related to greater social anomy.

The use of social media for social and political issues among youth is a variable that influences the perception of good citizenship of young people (see Fig. 6). In this regard, those countries where students declared greater use of the internet to search for information, or to share or comment on social or political issues, also show high percentages of students in the comprehensive profile. According to Castells' positive vision, where technology "reconnects" citizens instead of moving them

\footnotetext{
${ }^{6}$ Results available upon request to authors.
} 


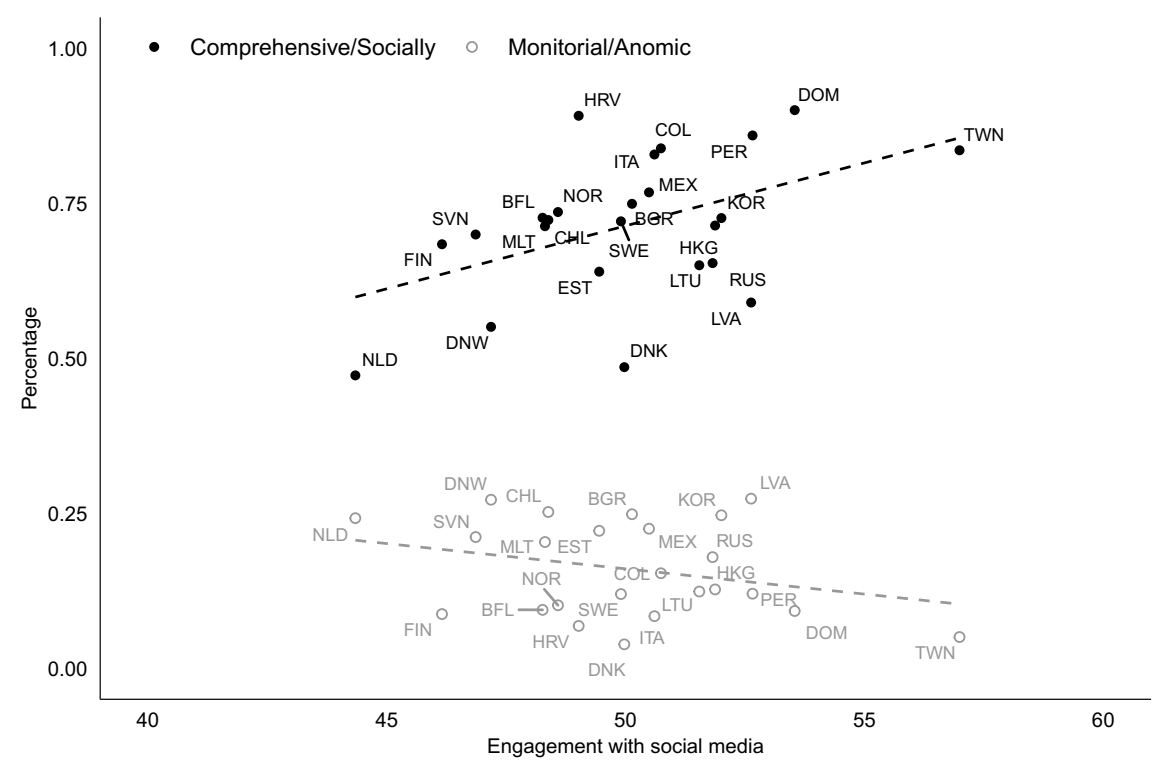

Fig. 6 Relationship between comprehensive and monitorial/anomic profiles and students' engagement with social media. Notes LVA = Latvia, DNW = North Rhine-Westphalia, BGR = Bulgaria, $\mathrm{KOR}=$ Korea, $\mathrm{MEX}=$ Mexico, $\mathrm{EST}=$ Estonia, $\mathrm{NLD}=$ The Netherlands, $\mathrm{CHL}=$ Chile, $\mathrm{SVN}=$ Slovenia, MLT $=$ Malta, RUS $=$ Russia, $\mathrm{COL}=$ Colombia, $\mathrm{PER}=$ Peru, $\mathrm{LTU}=$ Lithuania, $\mathrm{DOM}$ $=$ Dominican Republic, ITA $=$ Italy, $\mathrm{SWE}=$ Sweden, $\mathrm{NOR}=$ Norway, $\mathrm{BFL}=$ Belgium $($ Flemish $)$, $\mathrm{HKG}=$ Hong Kong, HRV $=$ Croatia, FIN $=$ Finland, DNK $=$ Denmark, TWN $=$ Chinese Taipei

away, participation through social media and the internet favors an active type of citizenship that entails a personal expressive and self-actualizing kind of political affiliation (Bennett et al. 2009). However, and beyond the scope of this book, it is important to mention that recent scandals regarding the manipulation of social media to influence elections pose a challenge regarding the critical use of social media by citizens.

Finally, the political dimension is studied from the premise that a "bad government" may influence young people's vision of citizenship. In this way, the neopatrimonialism index, which combines variables related to clientelist political relationships, strong and unconstrained presidential power, and the use of public resources for political legitimation, was used to measure negative aspects of governments. Due to the high correlation of the indices that integrate the neopatrimonialism index, the distribution of the good citizenship profiles behaves in a similar way when measuring profiles by the level of presidentialism, clientelism, and corruption of the countries. ${ }^{7}$ The main result (see Fig. 7) is that the higher the neopatrimonialism in the country, the higher the percentage of comprehensive students. As few countries have a high neopatrimonialism score, it cannot be indicated that a better government necessarily implies more widespread presence of comprehensive students.

\footnotetext{
${ }^{7}$ Results available upon request to authors.
} 


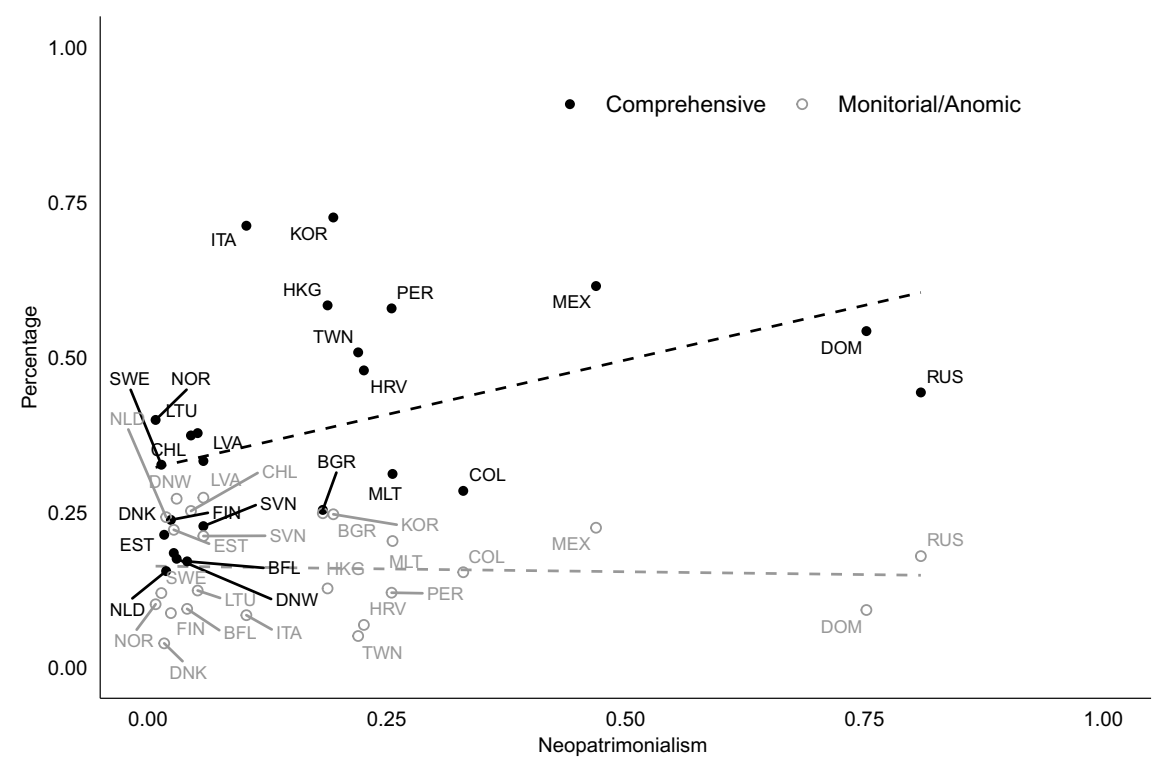

Fig. 7 Relationship between comprehensive and monitorial/anomic profiles and neopatrimonialism index. Notes LVA = Latvia, DNW = North Rhine-Westphalia, BGR $=$ Bulgaria, KOR $=$ Korea, $\mathrm{MEX}=$ Mexico, $\mathrm{EST}=$ Estonia, $\mathrm{NLD}=$ The Netherlands, $\mathrm{CHL}=$ Chile, $\mathrm{SVN}=$ Slovenia, $\mathrm{MLT}$ $=$ Malta, $\mathrm{RUS}=$ Russia, $\mathrm{COL}=$ Colombia, $\mathrm{PER}=$ Peru, $\mathrm{LTU}=$ Lithuania, $\mathrm{DOM}=$ Dominican Republic, ITA = Italy, SWE $=$ Sweden, $\mathrm{NOR}=$ Norway, $\mathrm{BFL}=$ Belgium $($ Flemish $), \mathrm{HKG}=$ Hong Kong, $\mathrm{HRV}=$ Croatia, FIN $=$ Finland, $\mathrm{DNK}=$ Denmark, $\mathrm{TWN}=$ Chinese Taipei

\section{Conclusions}

The aim of this chapter is to analyze in comparative terms the distribution of profiles of good citizenship among the 24 countries of ICCS 2016. The results show that, although there are common patterns among all or most countries (low proportion in the anomic profile, high proportion in the comprehensive and socially-engaged profiles), there are also relevant differences in the distribution of students across countries, depending on the geographic location and type of government regime. Additionally, the results show that the three groups of factors analyzed (economic, political, and cultural) are related to the distribution of good citizenship profiles. This allows us to conclude that, in comparative terms, the idea of good citizenship does not only depend on a single group of variables, but it is a construct determined by a complex array of variables pertaining to different fields.

Two variables analyzed are especially relevant. On the one hand, the relationship between income and good citizenship profiles creates some doubt regarding the growth of post-materialist values in the richest countries, although the most holistic profiles are found in European countries with high national income, such as Norway. On the other hand, the relationship between social and political use of social media (especially the internet) and profiles of good citizenship confirms the transformative 
potential of these technological tools in contemporary society. Although these are relevant topics for political science and sociology, these discussions are missing in the educational field, so these results can be understood as an invitation to deepen them.

Although potentially illuminating, an analysis of the results should also consider the limitations of the study. The comparative method tends to be correlational, so it is not possible to establish causation processes or multiple correlations. Additionally, the number of countries participating in ICCS 2016 is limited, without including entire geographical regions, such as Africa or the Middle East. Finally, the selected method seeks to deepen the analysis between countries, without entering into the variability of the profiles that exist in different schools or within schools.

Acknowledgements The authors would like to thank their research sponsors, the Center for Educational Justice ANID PIA CIE160007, as well as the Chilean National Agency of Research and Development through the grant ANID/FONDECYT $\mathrm{N}^{\circ} 1180667$, and ANID/FONDECYT $\mathrm{N}^{\circ}$ 11180792 .

\section{References}

Adler, S., \& Moi, K. (2011). Educating citizens: A cross-cultural conversation. Journal of International Studies, 1(2), 2-20.

Altikulaç, A. (2016). Patriotism and global citizenship as values: A research on social studies teacher candidates. Journal of Education and Practice, 7(36), 26-33.

Anderson, B. (1983). Imagined communities. Reflections of the origin and the spread of nationalism. New York, NY: Verso.

Atkinson, A., \& Piketty, T. (Eds.). (2010). Top incomes: A global perspective. Oxford, United Kingdom: Oxford University Press.

Atkinson, L. (2012). Buying into social change: How private consumption choices engender concern for the collective. Annals of the American Academy of Political and Social Science, 644(1), 191-206. https://doi.org/10.1177/0002716212448366.

Bennett, W. L., Wells, C., \& Rank, A. (2009). Young citizens and civic learning: Two paradigms of citizenship in the digital age. Citizenship Studies, 13(2), 105-120. https://doi.org/10.1080/136 21020902731116.

Bolzendahl, C., \& Coffé, H. (2009). Citizenship beyond politics: The importance of political, civil and social rights and responsibilities among women and men. British Journal of Sociology, 60(4), 763-791. https://doi.org/10.1111/j.1468-4446.2009.01274.x.

Bray, M., Adamson, B., \& Mason, M. (Eds.). (2014). Comparative education research (2nd ed.). Cham, Switzerland: Springer.

Castells, M. (2015). Networks of outrage and hope: Social movements in the internet age. Malden, MA: Polity Press.

Chang, W. C. (2016). Culture, citizenship norms, and political participation: Empirical evidence from Taiwan. Japanese Journal of Political Science, 17(2), 256-277. https://doi.org/10.1017/s14 68109916000062.

Coppedge, M., Gerring, J., Knutsen, C. H., Lindberg, S. I., Teorell, J., Altman, D., \& Ziblatt, D. (2019). V-Dem 2019 Dataset v9. https://doi.org/10.23696/vdemcy19.

Dalton, R. J. (2008). Citizenship norms and the expansion of political participation. Political Studies, 56(1), 76-98. 
Dalton, R. J., \& Ong, N.-N. (2005). Authority-orientations and democratic attitudes: A test of the "asian values" hypothesis. Japan, 6(2), 1-21. https://doi.org/10.1017/S1468109905001842.

Eder, A. (2017). Cross-country variation in people's attitudes toward citizens' rights and obligations: A descriptive overview based on data from the ISSP Citizenship Module 2014. International Journal of Sociology, 47(1), 10-25. https://doi.org/10.1080/00207659.2017.1265309.

Esteban, J., Mayoral, L., \& Ray, D. (2012). Ethnicity and conflict: An empirical study. American Economic Review, 102(4), 1310-1342. https://doi.org/10.1257/aer.102.4.1310.

Esteban, J., \& Ray, D. (2011). Linking conflict to inequality and polarization. American Economic Review, 101(4), 1345-1374. https://doi.org/10.1257/aer.101.4.1345.

Fairbrother, G. P. (2014). Quantitative and qualitative approaches to comparative education. In M. Bray, B. Adamson, \& M. Mason (Eds.), Comparative education research (2nd ed., pp. 71-93). Cham, Switzerland: Springer.

Fernández, C., \& Kriegbaum, K. (2017). The civic integrationist turn in Danish and Swedish school politics. Comparative Migration Studies, 5(1). https://doi.org/10.1186/s40878-017-0049-z.

Goering, E. M. (2013). Engaging citizens: A cross cultural comparison of youth definitions of engaged citizenship. Universal Journal of Educational Research, 1(3), 175-184. https://doi.org/ 10.13189/ujer.2013.010306.

Hobsbawm, E. (2013). Guerra y paz en el siglo XXI [War and peace in the 21 st century]. Barcelona, Spain: Crítica.

Hooghe, M., Oser, J., \& Marien, S. (2016). A comparative analysis of 'good citizenship': A latent class analysis of adolescents' citizenship norms in 38 countries. International Political Science Review, 37(1), 115-129. https://doi.org/10.1177/0192512114541562.

Inglehart, R. (1971). The silent revolution in Europe: Intergenerational change in post-industrial societies. American Political Science Review, 65(4), 991-1017. https://doi.org/10.2307/1953494.

Inglehart, R. (1979). Political action: The impact of values, cognitive level, and social background. In S. H. Barnes, M. Kaase, K. R. Allerback, B. Farah, F. Heunks, R. Inglehart, \& L. Rosenmayr, (Eds.), Political action: Mass participation in five western democracies (pp. 343-380). Beverly Hills, CA: Sage.

Kennelly, J. (2011). Citizen youth: Culture, activism and agency in a neoliberal era. New York, NY: Palgrave-MacMillan.

Klein, N. (2017). This changes everything: Capitalism vs. the climate. London, United Kingdom: Penguin.

Kuang, X., \& Kennedy, K. J. (2014). Asian students' perceptions of "good" citizenship: The role of democratic values and attitudes to traditional culture. Asia Pacific Journal of Educational Development (APJED), 1(June), 33-42. https://doi.org/10.6228/APJED.03.01.04.

Manzon, M. (2014). Comparing places. In M. Bray, B. Adamson, \& M. Mason (Eds.), Comparative education Research (2nd ed., pp. 97-137). Cham, Switzerland: Springer.

Mayne, Q., \& Geißel, B. (2018). Don't good democracies need “good" citizens? Citizen dispositions and the study of democratic quality. Politics and Governance, 6(1), 33-47. https://doi.org/10. 17645/pag.v6i1.1216.

Morozov, E. (2011). The Net delusion: The dark side of internet freedom. New York, NY: Public Affairs.

Russell, S. G., \& Quaynor, L. (2017). Constructing citizenship in post-conflict contexts: The cases of Liberia and Rwanda. Globalisation, Societies and Education, 15(2), 248-270. https://doi.org/ 10.1080/14767724.2016.1195723.

Schulz, W., Ainley, J., Fraillon, J., Losito, B., Agrusti, G., \& Friedman, T. (2018). ICCS 2016 international report: Becoming citizens in a changing world. Cham, Switzerland: Springer.

Soriano, M. (2013). Internet as a driver of political change: Cyber-pessimist and cyber-optimist. Revista Del Instituto Español de Estudios Estratégicos, 1, 332-352. 
Tesei, A. (2014). Trust, racial fragmentation and income inequality: New Evidence from the US. CESifo Working Paper No. 4718. https://www.cesifo.org/DocDL/cesifo1_wp4718.pdf.

Woolf, M. (2010). Another mishegas: Global citizenship. Frontiers: The Interdisciplinary Journal of Study Abroad, 19, 47-60.

Yamamura, E. (2008). The effects of inequality, fragmentation, and social capital on collective action in a homogeneous society: Analyzing responses to the 2005 Japan Census. Journal of Socio-Economics, 37(5), 2054-2058. https://doi.org/10.1016/j.socec.2007.10.003.

Cristóbal Villalobos is Associate Researcher at Centro de Estudios de Políticas y Prácticas en Educación (CEPPE UC), at Pontificia Universidad Católica de Chile. He holds a Doctoral degree in Social Science from the Universidad de Chile, a Master in Applied Economics at Universidad Alberto Hurtado, and a BA in Sociology and Social Work from Pontificia Universidad Católica de Chile. His research work focuses on social movements in education, educational inequalities, and citizenship education.

María Jesús Morel is Adjunt Research at Centro de Estudios de Políticas y Prácticas en Educación (CEPPE UC), at Pontificia Universidad Católica de Chile. She holds a BA in Sociology from Pontificia Universidad Católica de Chile. Her research work focuses on citizenship education.

Ernesto Treviño is Associate Professor at the School of Education at Pontificia Universidad Católica de Chile. He is Principal Investigator at the Center for Educational Justice, and director at Centro para la Transformación Educativa (CENTRE UC). He holds a Doctorate in Education from Harvard University, US. His research interest includes education inequalities, public policy in education, and citizenship education.

Open Access This chapter is licensed under the terms of the Creative Commons AttributionNonCommercial 4.0 International License (http://creativecommons.org/licenses/by-nc/4.0/), which permits any noncommercial use, sharing, adaptation, distribution and reproduction in any medium or format, as long as you give appropriate credit to the original author(s) and the source, provide a link to the Creative Commons license and indicate if changes were made.

The images or other third party material in this chapter are included in the chapter's Creative Commons license, unless indicated otherwise in a credit line to the material. If material is not included in the chapter's Creative Commons license and your intended use is not permitted by statutory regulation or exceeds the permitted use, you will need to obtain permission directly from the copyright holder. 